\title{
A FinAlidade MORAL do FAZER SOCIOLÓGICO: SOBRE OS SENTIDOS DO CONCEITO DE NORMAL EM Émile DURKHEIM
}

\author{
LUCAS HERTZOG ${ }^{1}$ \\ RaQuel ANDRADE WeISS ${ }^{2}$
}

\begin{abstract}
Resumo
Nosso propósito neste artigo consiste em avaliar criticamente o conceito de normalidade na teoria de Émile Durkheim para além do desenvolvimento realizado em As regras do método sociológico. Esperamos explicitar que o conceito de "normal" é um assunto central na teoria do autor, e traz consigo um inesperado potencial crítico, na medida em que sustenta a possibilidade de uma finalidade prática para a ciência, fornece critérios para se conceber a ação e a mudança social e, especialmente, permite avaliar de forma crítica as condições de possibilidade de solidariedade social para além da ideia de um mero consenso tácito.
\end{abstract}

Palavras-chave: Durkheim. Normal. Sociologia da moral. Patologia social.

\footnotetext{
1 Doutorando em Sociologia pela Universidade Federal do Rio Grande do Sul, Brasil. ramos.lh@gmail.com

2 Professora-Adjunta do Programa de Pós-Graduação de Sociologia da Universidade Federal do Rio Grande do Sul, Brasil. weiss.raquel@gmail.com
} 


\title{
SOCIOLOGICAL MORAL PURPOSE: ON THE MEANINGS OF THE NORMAL CONCEPT IN ÉMILE DURKHEIM'S THEORY
}

\begin{abstract}
This article aims to critically evaluate the concept of normality within Émile Durkheim's theory beyond the development held in the book "The Rules of Sociological Method". We intend to explain that the "normal" concept is a central issue for Durkheim's theory, bringing an unexpected critical potential, because it supports the possibility of a practical purpose for science, provides criteria for designing action and social change and allows to critically access the conditions to achieve social solidarity apart from the mere idea of a tacit consensus.
\end{abstract}

Keywords: Durkheim. Normal. Sociology of morality. Social pathology.

\section{INTRODUÇão}

A sociologia durkheimiana ficou conhecida na tradição sociológica sob inúmeros epítetos que, de algum modo, buscavam resumir as suas premissas teóricas, apresentadas a partir de um viés interpretativo reducionista e, muitas vezes, equivocado. Não raro, trata-se do efeito de situar o autor de um ou outro lado dos muitos debates travados no decorrer das Ciências Sociais, como aqueles entre explicação versus compreensão, estrutura versus ação e ordem versus conflitualidade. Sem dúvida, uma das formas mais difundidas de caracterizar de forma sumária o sociólogo francês foi designando-o como "o teórico da ordem", o que implicaria a premissa interpretativa de que sua sociologia seria marcada pela apologia da ordem e pela defesa da manutenção do status quo (NISBET, 1952; PARSONS, 1968).

Dentre as muitas explicações para a construção desse “Durkheim Mitológico" (WATTS MILLER, 2009, 2012), podemos indicar, por exemplo, a identificação entre Émile Durkheim e Auguste Comte, como discutiremos mais adiante, e a leitura peculiar feita por 
Talcott Parsons (1968), que se consolidou como uma interpretação canônica e bastante influente (JONES, 2001). E, certamente, podemos encontrar na obra do próprio autor algumas afirmações que, tomadas de forma isolada ou a partir de uma leitura apressada, realmente dão base para considerações dessa natureza. Um dos conceitos mais mobilizados para subsidiar a interpretação de Durkheim enquanto "teórico da ordem" é seu conceito de "normal", tal qual apresentado no capítulo três de As Regras do Método Sociológico (2007), em que o autor parece afirmar que a função da sociologia é defender a funcionalidade da ordem social, qualquer que seja esta.

Nosso propósito neste artigo consiste em avaliar criticamente o conceito de normalidade na teoria de Émile Durkheim para além do desenvolvimento realizado em As regras do método sociológico. Nortearemos nossa reflexão em torno da seguinte pergunta-chave: que outros sentidos podemos considerar sobre o conceito do "normal" na teoria durkheimiana?

Esperamos explicitar que o "normal" é um assunto central na teoria do autor, e traz consigo um inesperado potencial crítico, na medida em que sustenta a possibilidade de uma finalidade prática para a ciência, fornece critérios para se conceber a ação e a mudança social e, especialmente, permite avaliar de forma crítica as condições de possibilidade de solidariedade social para além da ideia de um mero consenso tácito. Além disso, trata-se de um conceito chave enquanto contraponto necessário da categoria de desvio, chamando a atenção para o fato de que qualquer discussão substantiva sobre qualquer forma de desvio social pressupõe que se leve em consideração os padrões que impõe determinado modo de vida como socialmente desejável. Em suma, o objetivo aqui é trazer alguns elementos e questionamentos que auxiliem numa reconsideração da teoria durkheimiana, buscando problematizar a subsistência de algumas perspectivas analíticas 
resultante da autoridade advinda de teorias que encapsulam apenas parte de seu pensamento (JONES, 2001, p. 22).

\section{ReCONSTRUÇÃo dAS PERSPECTIVAS CRíticAS}

A confusão teórica acerca dos conceitos normal e patológico resulta precisamente da opacidade com a qual Durkheim tratou a questão em "As regras", onde o normal é associado com a ordem e o patológico com a perturbação da mesma. Steven Lukes (1985, p. 29) sugere que as dificuldades surgem ao ver o normal como a média e o patológico como a divergência deste padrão. Esta visão é amplamente criticada - até mesmo com razão em muitas ocasiões -, pois incitaria um pensamento normativo preocupado com a manutenção das organizações sociais vigentes, advindo da assunção de que o tipo médio encontrado em determinada organização social e tempo histórico constituiria o que é normal. Habita aqui um grande vácuo explicativo que não contempla a totalidade do conceito na obra durkheimiana, o que só pode ser suprimido através de uma procura mais aguçada em outras ideias desenvolvidas.

Uma explicação mais acurada sobre o sentido do normal pode ser encontrada nos desdobramentos de sua teoria da moral, o que só pode ser associado através de ideias expostas em outros textos que abarcam uma perspectiva mais ampla e que incluam questões sobre o fazer científico e o papel da ciência na prática e sobre a relevância da consciência individual, da qual tudo emanaria previamente a qualquer atuação no desenvolvimento das sociedades (JONES, 2001, p. 31). Esse déficit compreensivo suscitou diversas interpretações tomadas por seus comentadores, associando a teoria durkheimiana especialmente com o conservadorismo e o positivismo (ARON, 2002; NISBET, 1952; PARSONS, 1968). 
No intuito de enriquecer este debate, propomos retomar algumas questões centrais à assimilação de alguns pontos discutidos por este pensador clássico da Sociologia. O que torna Durkheim um clássico nas Ciências Sociais e no pensamento em Humanidades não é apenas seu caráter fundador, mas substancialmente a atualidade que suas ideias apresentam na verificação e no debate de temas contemporâneos. Sua sociologia da moral é fundamental na compreensão de períodos transitórios e de crise (sendo a dinamicidade uma das características centrais da modernidade), o que justifica um esforço teórico no intuito de perceber o sentido do que é o normal e o patológico a partir de sua concepção.

Para delimitar este percurso analítico exploratório, buscaremos inicialmente trazer a discussão que Durkheim iniciou em sua tese latina sobre a teoria política de Montesquieu³. Nela, uma dos questionamentos fundamentais é aquele sobre a distinção entre ciência e arte: qual é o papel da ciência e o que a diferencia da arte? Embasado nesta perspectiva epistemológica que delineia os contornos do papel do cientista, tentaremos argumentar que há elementos substanciais de superação ao positivismo comteano. Este percurso tem a finalidade de sedimentar os pressupostos compreensivos do argumento acerca do sentido mais complexo do conceito de normal na teoria durkheimiana. Como primeiro passo, é necessário recorrer ao desenvolvimento exposto em As regras, afinal, mesmo que existam divergências quanto aos seus desdobramentos teóricos, pois ele é fundamental para um primeiro olhar sobre o conceito.

Nesse percurso, o diálogo com os intérpretes é um elemento crucial, na medida em que se trata de compreender elementos centrais

Trata-se da tese secundária, apresentada junto à tese principal, que deveria ser escrita em latim. Na literatura especializada refere-se a este trabalho, Quid Secondatus politicae scientiae instituendae contulerit, simplesmente como "A tese latina", ou "A tese sobre Montesquieu". A versão aqui utilizada é a tradução para o inglês, organizada por William Watts Miller em edição bilíngue (DURKHEIM; WATTS MILLER, 1997). 
da história das análises que levaram à cristalização de certas leituras e, por outro lado, buscar na literatura mais recente insights que ajudem no processo de ampliação e ressignificação desse conceito. Trata-se não apenas de investigar os significados do conceito de normal, mas também repensar os limites de sua relação com a filosofia comteana, incluindo outros autores no rol daqueles que exerceram um impacto decisivo em seu pensamento e, além disso, considerar as implicações de sua premissa acerca da finalidade prática da ciência, bem como acerca dos limites desta. Essa última consideração está intrinsecamente vinculada à primeira, na medida em que pressupõe a compreensão de que foi sobretudo Charles Renouvier, mais do que Auguste Comte, que exerceu um impacto decisivo em sua compreensão do que é a Ciência e de sua relação possível e desejável com o universo social (JONES, 2001; MASSELLA, 2006).

\section{A ideia de normalidade e A fUnção prática da CiênCia}

Na introdução à sua tese de doutorado, Da Divisão do Trabalho Social, Durkheim afirma que a prática da ciência não mereceria sequer uma hora de nossos esforços se não fosse capaz de ajudar-nos a encontrar o melhor caminho a ser seguido. Por outro lado, em sua tese latina, o autor inicia recorrendo à ideia de que o fazer científico deveria libertar-se da arte, ao passo que a Ciência deveria descrever tipos sociais, não individuais. Trata-se, portanto, de duas afirmações aparentemente contraditórias, cuja devida compreensão é a chave para desvendar o projeto durkheimiano e de sua concepção de Ciência enquanto uma atividade que deveria ser capaz de fornecer elementos para auxiliar em nossas atividades práticas, embora ela mesma não tenha o mesmo caráter que a arte. É precisamente nessa tensão entre finalidade prática e atividade prática que se põe o pleno significado do conceito de normal, enquanto conceito que permite à Ciência encontrar 
um dispositivo que auxilie os indivíduos de uma dada sociedade em sua árdua tarefa de decidir qual caminho seguir. Trata-se de um conceito que se pretende investido de um potencial normativo, uma vez que deveria permitir uma forma de avaliar a realidade social a partir de critérios que lhe são imanentes.

No que se refere à arte, é preciso ter-se em consideração que, no contexto do século XIX, ela era definida como uma atividade essencialmente prática ou que possuía uma finalidade diretamente prática. A engenharia, por exemplo, era pensada como uma arte, na medida em que usa conhecimentos da matemática e da física de forma aplicada e sua razão de ser é construir objetos materiais [ação]. Outro exemplo seria a medicina, que mobiliza conhecimentos de várias áreas com a finalidade de sistematizá-los para serem aplicados na prática médica. Muitas vezes, ela sugere práticas que não foram suficientemente testadas, ou coisas que se sabe que funciona, ainda que não se saiba racionalmente suas explicações, seus porquês.

As "Ciências" no registro do XIX eram entendidas como uma forma de reflexão sobre o mundo, com finalidade primariamente teórica, ou seja, descobrir as leis do mundo, saber como funcionam as coisas, mesmo que sua utilidade imediata não seja clara. A Ciência não pode sacrificar a sua busca pela "verdade" para satisfazer alguma necessidade prática. Do ponto de vista da Ciência, é legítimo se investigar qual a origem do universo, mesmo que nesse momento essa questão não tenha uma aplicação prática. Já no caso da sociologia, ela deveria buscar conhecer a realidade social mesmo que o resultado de seu conhecimento fosse desagradável.

A discussão sobre sociologia da educação e pedagogia elucida essa tensão existente entre a finalidade prática das artes e do fazer científico (SILVA, 1980; WEISS, 2009, p. 169-186). A sociologia da educação tem o seu tempo e pode ser que demore muito até conseguir fazer um levantamento exaustivo de todos os sistemas educacionais 
existentes, demonstrando sua origem e sua finalidade. Entretanto, a pedagogia não pode esperar até os últimos avanços da sociologia da educação, ao passo que ela precisa orientar a prática educativa "aqui e agora". Há crianças que precisam ser educadas, elas não podem esperar mais quinze ou trinta anos até que resultados mais conclusivos sejam obtidos. O que a pedagogia pode e deve fazer é compilar os conhecimentos das várias ciências que estão à sua disposição nesse momento e tentar embasar nesses conhecimentos (da sociologia, história, psicologia) as decisões sobre a melhor forma de educar as crianças. A arte tem pressa, a Ciência segue outro tempo. Mas a arte busca referência na Ciência, e a Ciência deve tentar dialogar com a arte (DURKHEIM, 1922).

Nesta percepção sobre o papel do cientista e sobre a finalidade da Ciência em contraposição à arte, Durkheim foi fortemente influenciado pelas ideias de Charles Renouvier. Sendo um dos principais ideólogos da República, ele defendia que era obrigação moral dos cientistas contribuírem para a consolidação da mesma e isso deveria ser feito na medida em que tornassem públicos os seus procedimentos: era a ideia de que a Ciência é uma prática racional e que ao trazer racionalidade para o mundo, tornar mais explícito o modo como funciona a natureza, seria ampliada a crítica à religião e se abriria mais espaço para a razão (RENOUVIER, 1869).

É aqui que entra um segundo sentido de prática, ligado à ideia kantiana que identifica prática com moral (KANT, 2008), tendo em Renouvier um dos principais idealizadores (LOGUE, 1993). É um pouco isso o que Durkheim tem em mente quando fala na divisão social do trabalho, que as nossas investigações científicas não mereceriam uma hora de nosso esforço se não tivessem uma finalidade prática (DURKHEIM, 1999). Residiria nesta ideia a herança kantiana sobre o primado da prática. A Ciência, em última instância, precisa ter uma finalidade moral, ainda que essa finalidade seja atingida justamente 
perseguindo sua finalidade teórica. Ou seja, quanto melhor eu conheço a sociedade, quanto mais desvendo seu rationale $e^{4}$ mais contribuo para ela, ainda que minhas pesquisas não sejam orientadas para reformas imediatas, como é o caso da arte.

É da necessidade de uma finalidade moral da prática científica que Durkheim busca a distinção entre o estado normal do patológico, não de uma finalidade prática utilitarista (ou de manutenção da ordem, preocupada com o status quo):

[...] se há interesse em distinguir o normal do anormal, é sobretudo com vistas a esclarecer a prática. Ora, para agir com conhecimento de causa não basta saber o que devemos querer, mas por que o devemos. As proposições científicas, relativas ao estado normal, serão mais imediatamente aplicáveis aos casos particulares quando estiverem acompanhadas de suas razões; pois então saberemos reconhecer melhor em que casos convém modifica-las, ao aplicá-las, e em que sentido (DURKHEIM, 2007, p. 62).

Há, então, uma conciliação entre a finalidade prática e teórica do fazer científico: ao mesmo tempo em que persegue a consecução de sua finalidade teórica propondo esclarecer os estados normais dos anormais, auxilia o desenvolvimento integral da República mediante suas proposições práticas (RENOUVIER, 1848). Mas não há possibilidade, para Durkheim, de realizar uma definição abstrata sobre estes estados normais e anormais, já que as condições de saúde e doença não podem ser definidas in abstracto e de maneira absoluta. Para ele "é preciso renunciar a esse hábito, ainda muito difundido, de julgar uma instituição, uma prática, uma máxima moral, como se

$4 \quad$ Significado do termo em Weiss (2010) e Watts Miller (1996). 
elas fossem boas ou más em si mesmas e por si mesmas, para todos os tipos sociais indistintamente." (DURKHEIM, 2007, p. 59).

O significado dessa formulação é uma compreensão acerca da finalidade prática da ciência que o afasta tanto do positivismo comteano, no âmbito do qual a sociologia seria capaz de apreender as leis da dinâmica histórica a partir de uma perspectiva teleológica, quanto de uma noção propriamente kantiana, em que a razão teórica não teria condições de informar sobre a vida moral, o que seria prerrogativa exclusiva da razão prática. Do mesmo modo, a ideia durkheimiana sobre a finalidade prática não significa que a ciência tem a prerrogativa de propor uma ética, tal como defendera Parsons, afirmando que por trás da distinção entre normal e patológico "existiria a ideia de que é possível desenvolver uma ética totalmente científica para que as teorias científicas passem a ser não apenas elementos indispensáveis para a determinação da ação racional, mas também os únicos elementos adequados para isso." (PARSONS, 1968, p. 501).

Mais especificamente, isso quer dizer que a ciência não propõe uma moral, o que seria o caso de uma "ética científica", como sugere Parsons. Ela tão somente pode ser um instrumento para a prática na medida em que permite aos indivíduos de uma certa sociedade compreender se as regras morais que vigoram em sua sociedade estão em consonância com a composição desse sociedade e com os ideais criados por essa sociedade. Em suma, o normal refere-se ao conjunto de fatos que "são o que deveriam ser". Por exemplo, no contexto de uma sociedade constituída sobre o ideal da dignidade humana, podem ser consideradas normais todas as regras, práticas e instituições que promovam esse valor, tais como mecanismos de promoção da igualdade social, do direito à identidade cultural e religiosa, de viver conforme sua orientação sexual, etc. Nesse mesmo tipo de sociedade, pode ser que existam instituições e regras e práticas que sejam contrárias a esse princípio, ainda que sejam amplamente difundidas, 
como quaisquer mecanismos que promovam a desigualdade social ou cerceiem direitos individuais. São fatos desse tipo que a sociologia da moral de matriz durkheimiana poderia considerar como patológicos.

Portanto, isso exclui a ideia de uma ética substantiva; não há máximas morais superiores e universalizáveis, já que cada sociedade passa por diferentes tensões morais em consonância com seu momento histórico e especificidade. Por outro lado, há a tentativa de encontrar critérios imanentes que permitam avaliar uma sociedade a partir de sua própria lógica interna. Sem dúvida, isso representa um distanciamento com o positivismo de Comte, que almejava o alcance de um estado positivo e ulterior ao estágio em que se vive (COMTE, 1978). Para aprofundar o significado desse distanciamento, propomos a seguir uma reflexão sobre outros pontos nos quais há uma cisão com o positivismo e que possibilitam pensarmos a passagem do "é" para o "dever ser" moral em Durkheim, sem que haja nisso uma implicação conservadora ou o desenvolvimento de uma falácia naturalista.

\section{Distanciamento de Auguste Comte}

A disseminação da ideia de que o pensamento durkheimiano está embebido em um positivismo comteano se deve mais ao impacto do conteúdo existente na obra de comentadores do que propriamente no projeto científico desenvolvido por Durkheim, conforme tem sido amplamente sublinhado pela literatura especializada que se consolidou nas últimas três décadas, que se apoia em uma leitura de um conjunto mais amplos de textos, de análises do contexto intelectual e histórico e em novas descobertas documentais (ALEXANDER, 1988; BESNARD; BORLANDI; BUSINO, 2004; BESNARD; BORLANDI; VOGT, 1993; JONES, 1995; JONES, 2001; WATTS MILLER, 2012; RILEY, 2002; ROSATI; SANTAMBROGIO; ALEXANDER, 2002; ROSATI, 2009; WEISS; BENTHIEN, 2012). Certamente há diversos elementos 
convergentes na obra dos dois autores, mas há, sobretudo, diversos pontos de cisão interpretativa que demonstram uma larga distância em questões fundamentais. Uma das leituras que mais influenciou esse universo interpretativo foi a de Talcott Parsons, sobretudo em sua obra mais conhecida, A Estrutura da Ação Social, que se firmou como a principal referência para a interpretação dos clássicos ao longo de várias décadas. Conforme observam Joas e Knöbl (2009), essa influência foi decisiva para a assimilação da obra durkheimiana nos Estados Unidos, mas também foi a responsável pela leitura dos clássicos na Europa e em diversos países da América Latina, inclusive no Brasil. O elemento central de sua interpretação foi o argumento segundo o qual a temática central em Durkheim era uma preocupação com a ordem e que o fator diferencial mais importante entre a obra deste e a de Comte, foi sua capacidade de acompanhar esse problema até um nível muito mais profundo (PARSONS, 1968, p.460-470).

É difícil mensurar o impacto de Talcott Parsons nas representações coletivas dos sociólogos no que se refere a seu entendimento sobre a obra durkheimiana; mas, sem dúvida, tratase da interpretação mais decisiva na formação das representações coletivas que povoaram o imaginário sociológico entre as décadas de 1940 e 1980. Em muitos contextos, sua interpretação continua a orientar as leituras que se faz sobre o sentido da obra durkheimiana (JOAS; KNÖBL, 2009). Por isso, qualquer discussão que pretenda apresentar alguma inovação interpretativa pressupõe uma referência obrigatória às teses centrais de Parsons, uma vez que tais inovações são, de algum modo, respostas a uma leitura cristalizada e ainda muito influente. Segundo Jeffrey Alexander (1988), a "virada culturalista" da sociologia norte-americana só foi possível a partir de um acerto de contas com a interpretação parsoniana, para viabilizar um retorno à obra de Durkheim que não passasse pela consideração desse autor como um teórico da ordem. Afinal, após a emergência da chamada "sociologia 
do conflito", Durkheim fora identificado com o funcionalismo parsoniano, de modo que qualquer referência a esse autor precisava ser duramente criticada, pois significaria um comprometimento com forças sociais conservadoras.

Em suma, ainda que Parsons tenha tido inicialmente um impacto positivo, ao passo que possibilitou a disseminação de muitas obras e ideias de Durkheim, ele o fez de maneira bastante peculiar. Afinal, ao caracterizar Durkheim como um positivista comteano e como um "teórico da ordem", a obra durkheimiana ficou em clara desvantagem em contraste com Weber e Marx. Ainda, segundo Susan Jones (2001, p. 28):

\begin{abstract}
A leitura parsoniana induziu diversos leitores e comentadores a excluir a noção de mudança social de sua perspectiva, o que pode ser contestado através de contrapontos em sua teoria: 1) Conceito de mente e indeterminação: quanto mais especializadas as faculdades, mais fácil surgirá a mudança social; 2) Conceito da diferença: diferenciação na ordem social estimula mudanças; 3) Hábito: condições de vida não podem mudar drasticamente se o indivíduo é refém da tradição. Os hábitos resistem à mudança precisamente porque são 'obscuros'.
\end{abstract}

Susan Jones salienta que existem algumas características do pensamento comteano que eram admiradas por Durkheim, como a aplicação da Ciência e o conceito de lei para a sociedade; o sentimento vívido da realidade social e sua natureza histórica; o método comparativo; a preocupação com a solidariedade e sociabilidade (JONES, 2001, p. 29). Entretanto, algumas questões são fundamentais na diferenciação das ideias dos dois pensadores. Enquanto para Comte a humanidade forma um todo realizado, para Durkheim ela é configurada a partir de sociedades particulares e diferenciadas. Para 
este, "o todo não é apenas a soma das partes, mas algo diferente." (DURKHEIM, 2007). Comte pensava este todo em direção a um progresso contínuo por etapas, nas quais necessariamente todos os grupos humanos deveriam passar. Em Durkheim não há uma noção de progresso da humanidade: a mudança social é explicada a partir de uma lógica do "tornar-se". Para ele, tudo emana das consciências individuais até que um ideal, uma moral, torne-se prática no desenvolvimento das sociedades, podendo se diferenciar de forma não linear, assim "como uma árvore, com galhos espalhados em diferentes direções." (DURKHEIM, WATTS MILLER, 1997, p. 67e).

A percepção de que a preocupação central em Durkheim seria a manutenção da ordem, exclui a noção de mudança social que consideramos central em sua perspectiva. Para ele, quanto mais diferenciadas as sociedades modernas tornavam-se (com o aumento na divisão social do trabalho), maior seria a possibilidade de mudança social, uma vez que diversas morais entrariam em conflito de julgamento. Isso implica não apenas um afastamento de Durkheim em relação ao positivismo de Comte, mas também acarreta diferenças significativas quanto ao que Durkheim estabeleceu em seu conceito de normal.

Para Comte, o normal é a expressão do tipo médio: é estritamente numérico, a partir das ocorrências na sociedade. A percepção de Durkheim como um seguidor estrito de Comte, acarretaria na seguinte conclusão: o estado normal seria o que está estabelecido, sendo o estado patológico qualquer alteração neste estado contínuo. Mas, afinal, se Durkheim propusera em sua teoria uma perspectiva na qual tudo emanaria das consciências individuais possibilitando o desenvolvimento da psique coletiva, de que forma haveria mudança se estas consciências fossem estáticas, estagnadas num ponto específico? Se Durkheim estava realmente preocupado com o estabelecimento e manutenção da ordem, isto não entraria em 
contradição com sua ideia de que "as leis da sociedade podem ser quebradas, uma vez que o vigente não é necessariamente o lógico?” (DURKHEIM; WATTS MILLER, 1997, p. 64e)

$\mathrm{O}$ ponto central para entender as diversas confusões interpretativas com relação ao sentido da ideia de "normal" em Durkheim se deve sobretudo ao fato de que essa noção é apresentada de forma apenas parcial em As regras, que do livro no qual diversos autores, como Parsons, basearam sua concepção sobre o conceito do "normal". Nesse livro está ausente o argumento desenvolvido na tese latina, em que a ideia de normalidade é associada à noção de "lógica subjacente ao real". Na próxima seção buscaremos explicitar qual é o principal sentido do conceito de normal em As Regras, para entender o sentido geral do conceito nesse contexto para explicitar as lacunas deixadas pelo próprio autor, que não introduzem nessa obra argumentos desenvolvidos pouco tempo antes, e que talvez estivessem pressupostos quando de sua discussão, mas que foram ignorados por boa parte dos intérpretes, levando a um entendimento parcial a respeito da concepção durkheimiana acerca da função prática da ciência.

\section{O CONCEITO DE NORMAL EM "As REgRAS do MÉtOdo SOCIOlógico"}

Na literatura especializada há um consenso de que conceito de normal e a importância de distinção entre fenômenos normais dos patológicos estão intimamente ligados ao papel reformador da sociedade que Durkheim atribui à Ciência (GURVITCH, 1995; LACAPRA, 1972; TURNER, 1993; WALLWORK, 1972). Para Durkheim, a Sociologia não valeria de nada se não contribuísse para os esforços coletivos de transformação social. A utilização dos conceitos "normal" e "patológico", pode ser considerada tanto como instrumento 
metodológico na percepção de fenômenos, como ferramenta conceitual que auxilia na consecução dessa finalidade prática da ciência.

Mesmo que haja nesse espírito reformador uma noção de mudança social e que a questão que Durkheim coloca sobre a finalidade prática da Ciência seja coerente com o resto de As regras, o autor não expõe com suficiente clareza de que modo se cumpre essa finalidade. $\mathrm{Na}$ verdade, parece haver uma confusão entre os dois sentidos da ideia de normal, ora entendida como uma categoria oriunda da estatística, ora como uma categoria biológica, sem avisar ao leitor quando se trata de um ou outro registro. Grosso modo, a ideia de normal no sentido estatístico faz alusão à "curva normal", que distribui os fenômenos segundo a proporção de sua ocorrência. Por exemplo, num contexto em que $90 \%$ dos indivíduos sonegam impostos, a ação de sonegar impostos seria considerada normal, pois diria respeito a fenômenos com uma alta taxa de ocorrência. Aqueles cujo comportamento não corresponde a essa regularidade estatística seriam classificados como desviantes. No sentido biológico, o normal é entendido como aquilo que não é patológico, ou seja, aquilo que é considerado saudável, que não prejudica a vida do ser vivo, ainda que possa constituir uma anomalia do ponto de vista da regularidade estatística. Vamos supor uma sociedade em quem a média da altura dos homens seja de 1,70. Considerando-se o que é estabelecido como desvio padrão numa situação específica, aqueles que tiverem altura menor que 1,60 ou maior que 1,80 serão considerados desviantes do ponto de vista estatístico. Porém, essa característica biológica não tem nenhuma consequência para a saúde do indivíduo. Por outro lado, se um indivíduo nasce sem um dos órgãos vitais, seu estado é considerado patológico, e é necessário que exista alguma intervenção médica para garantir a sua sobrevivência.

No caso da discussão em questão, a ideia de normal em sentido biológico diz respeito aos fenômenos cuja existência coloca 
em risco a existência de determinado grupo devendo, portanto, ser considerado patológico. No entanto, em As Regras, a discussão padece de dois problemas. O primeiro, é que o autor não deixa claro quando um fenômeno pode ser considerado patológico, e porque o seria. $\mathrm{O}$ segundo, é que o autor não explicita em que momentos opera no registro biológico e quando transita para um uso no sentido estatístico. Aliás, o problema nesta obra é que Durkheim usa o tempo todo a metáfora biológica, mas na verdade usa como evidência o registro estatístico (DURKHEIM, 2007). Ou seja, ele propõe que determinemos se a coisa social é ou não saudável a partir da evidência de recorrências numérica. Entretanto, devemos pensar criticamente acerca destes critérios sobre os quais o conceito é estabelecido, devidamente posicionado em seu momento histórico.

Existem então, ao menos duas questões fundamentais na análise destes conceitos. Conforme mencionamos, no caso do registro biológico há diferenciação entre fenômenos saudáveis e patológicos. No registro de caráter estatístico, é normal o que é estatisticamente verificável como a média. Já neste posicionamento inicial podemos notar que são critérios amplamente distintos, pois há uma dupla aproximação: primeiramente com a lógica médica e em segundo lugar com a lógica matemática. Mais adiante, através de um movimento de abertura do conceito através da exposição de ideias da tese latina como sugere Watts Miller (1996), veremos que algo que é recorrente pode ser patológico e que às vezes há uma coincidência entre o normal estatístico e o normal do "dever ser", mas às vezes o normal estatístico é patológico (o que acontece quando uma sociedade está num processo de transformação específico). Entretanto, o que nos cabe aqui é desvelar precisamente as ideias que tanto problema causaram na apreensão da teoria durkheimiana.

A distinção entre saúde e doença é fundamental na concepção do que seria desejável para o funcionamento da sociedade. Através da 
analogia com as Ciências Biomédicas, Durkheim pensa que todas as coisas normais são saudáveis, ao passo que acontecimentos anormais caracterizariam um estado de doença. Para ele esta distinção possuía uma finalidade prática com propósito reformador, servindo como um critério avaliativo da situação de um fenômeno social:

[...] tanto para as sociedades como para os indivíduos, a saúde é boa e desejável, enquanto a doença é algo ruim e que deve ser evitado. Se encontrarmos portanto um critério objetivo, inerente aos fatos mesmos, que nos permita distinguir cientificamente a saúde da doença nas diversas ordens de fenômenos sociais, a ciência será capaz de esclarecer a prática, sem deixar de ser fiel ao seu próprio método (DURKHEIM, 2007, p. 51).

O cientista que se debruça sobre fenômenos sociais possui então um papel similar ao do médico quando este diagnostica problemas com seus pacientes. Caracterizada por uma realidade própria construída pela consciência coletiva, a sociedade para Durkheim compõe um corpus passível de diagnóstico, podendo a Sociologia "perfeitamente nos dizer de que maneira as causas produzem seus efeitos, não que finalidades devem ser buscadas" (DURKHEIM, 2007, p. 50). Assim como o diagnóstico médico sobre uma doença, o papel do cientista social é buscar a causalidade dos fenômenos sociais, estabelecendo assim, nexos lógicos explicativos para fenômenos que não contribuem ao funcionamento da sociedade. $\mathrm{O}$ que diferenciaria o diagnóstico médico do social é precisamente a finalidade prática dos mesmos: enquanto o médico busca soluções em curto prazo, a ciência busca respostas que não necessariamente terão aplicabilidade no momento, sendo legítimo o fazer científico quando este não está à mercê de uma finalidade última. O sentido da finalidade prática da ciência estaria 
na descoberta das causas dos fenômenos, conquanto ela possibilitasse a exposição das doenças e suas causas. Quanto à possibilidade de intervenção na realidade e como devemos proceder, Durkheim sugere que "deve-se recorrer às sugestões do inconsciente, não importa o nome que se dê a ele: sentimento, instinto, impulso vital etc." (DURKHEIM, 2007, p. 50), uma vez que a Ciência nos mostraria o que é, não o que é desejável. Nesse sentido a metáfora biológica seria a "fórmula" encontrada por Durkheim na busca de um critério universal de julgamento de fenômenos sociais que contribuem ao funcionamento da sociedade. Segundo La Capra (1972), este procedimento preocupa-se apenas com a forma e nunca com o conteúdo, o que seria problemático na medida em que nem tudo que contribui para o funcionamento da sociedade pode ser justificado.

Certamente há na metáfora médico-biológica grandes problemas. Entretanto, há um elemento decisivo que é a busca pela causa dos fenômenos, ou seja, Durkheim demonstra que o Cientista Social pode engajar-se em uma busca pelos elos causais explicativos da realidade social estabelecendo, assim, o primeiro passo na confrontação dos problemas que é o da sapiência dos mesmos. Mesmo que La Capra (1972) afirma que não há uma preocupação com o conteúdo, podemos ver que Durkheim não pensa em defini-los de maneira absoluta:

As condições da saúde e da doença não podem ser definidas in abstracto e de maneira absoluta. [...] É preciso renunciar a esse hábito, ainda muito difundido, de julgar uma instituição, uma prática, uma máxima moral, como se elas fossem boas ou más em si mesmas e por si mesmas, para todos os tipos sociais indistintamente (DURKHEIM, 2007, p. 59).

Mais do que um critério para definir o que é patológico e normal, estes conceitos são para Durkheim critérios de julgamento 
e distinção, que se põem em uso no momento em que há situações de instabilidade na vida social. Isso implica uma virada nas "representações coletivas" estabelecidas sobre Durkheim como um cientista da ordem, ao passo que ele não luta pela manutenção do status quo, e sim, pela compreensão da transitoriedade dos fenômenos a partir de sua aparência de normalidade. Pensar que Durkheim estabelece que o normal e o patológico sejam instâncias imutáveis é no mínimo ingênuo. Para ele o sociólogo poderia encontrar dificuldades de estabelecer o que é o estado normal em sociedades altamente diferenciadas ao passo que ele estaria privado de pontos de referência (DURKHEIM, 2007, p. 62). Nestes casos a generalidade é um "rótulo mentiroso, posto que, mantendo-se apenas pela força cega do hábito, ela não é mais o indicador de que o fenômeno observado está intimamente ligado às condições gerais da existência coletiva." (DURKHEIM, 2007, p. 62-63).

Tomar a generalidade do fenômeno como um critério de desejabilidade seria precisamente o que condenaria Durkheim a ser considerado como um conservador, na medida em que equivaleria a dizer que aquilo que é bom é aquilo que existe e que, portanto, deve ser conservado, de modo que qualquer movimento no sentido de transformação das regras ou instituições vigentes poderia ser entendido como ameaça a essa estabilidade. Afinal, ao definir que uma forma de organização social ou um fenômeno social são normais a partir de sua recorrência numérica, é implicitamente aceitar que eles estão contribuindo para o funcionamento desejável da sociedade tal qual esta está posta. Todavia, há uma transformação do conceito de normal, que podemos buscar em obras diferenciadas do autor, já que ele afirma que a lógica do real não é necessariamente coincidente com a lógica que ele pensava ser possível para a realidade social. 


\section{O NORMAl Que "é" E O “DeVEr SER"}

O conceito de normalidade adquire dois sentidos na obra durkheimiana. Como sugere Watts Miller (1996), há duas rotas para os sentidos do normal: o que "é" e o que "deve ser". O primeiro sentido está fortemente ligado àquilo que percebemos por intermédio da pesquisa sociológica através da construção de categorias generalizantes. $\mathrm{O}$ papel do sociólogo na verificação do que é normal se dá pela via da constatação que é encetada pela busca de regularidades na vida social, ou seja, são normais aquelas realidades ou comportamentos verificados empiricamente com um elevado grau de repetição.

Já expusemos que Durkheim foi fortemente influenciado por ideólogos da República como Charles Renouvier. Isso implica que ele não se contentava em pensar o fazer sociológico como mera constatação da realidade, ao passo que o empreendimento científico só valeria a pena na medida em que estimulasse aprendizados coletivos que trouxessem consigo a possibilidade de transformação social. Há nesse sentido um componente fundamental no qual se apoiaram diversas análises do pensamento durkheimiano que se preocupavam com a possibilidade de se pensar a normalidade numa perspectiva normativa ou, em outras palavras, em pensar sobre o que é normal a partir de critérios estabelecidos a priori. No recente período repressivo pelo qual passamos na história brasileira, certamente era demasiado perigoso abrir-se uma porta para o pensamento de que poderíamos espelhar numa teoria normativa na busca do estabelecimento do que é o "normal". Mas passados alguns anos o ideal democrático já inicia o estabelecimento de suas bases na consciência coletiva, então, nada mais frutífero que pensarmos neste tema tão caro e presente em toda a obra de Durkheim.

A insatisfação com as condições da modernidade está presente nas ideias de Durkheim como em muitos pensadores de seu tempo, o 
que influenciou tanto seu pensamento crítico acerca do fazer científico, quanto os caminhos que percorreu na busca de respostas. Ele escolheu a divisão social do trabalho para lançar luz sobre suas indagações, o que se verificou como um frutífero tema para seu desenvolvimento teórico. Para ele, ao mesmo tempo em que a intensa divisão social do trabalho poderia provocar mudanças positivas na realidade social, ela continha em si os maiores perigos que podem levar ao exacerbado individualismo, e que consequentemente, levariam a sociedade ao estado de anomia (DURKHEIM, 1999; WATTS MILLER, 2012). Há então na própria "coisa social" as possibilidades explicativas de suas causas, através de um movimento de percepção de sua dinâmica interna, sua lógica especifica.

Para Watts Miller uma das regras básicas do método sociológico em Durkheim parte da ideia de "buscar uma explicação internalista para as coisas - buscar dentro da própria natureza e dinâmica do mundo social as formas de explicar tanto seus ideais quanto suas patologias" (WATTS MILLER, 2009, p. 48). Olhar para o mundo moderno fazia com que Durkheim pensasse que a divisão social do trabalho produzia coisas normais e patológicas, sendo este um argumento que permeou toda a obra do autor. Isso tem largas implicações em sua posição ética, que está intimamente ligada com a finalidade prática que exploramos anteriormente:

Durkheim nunca abandonou sua ideia sobre o normal. Ele a desenvolveu no argumento central de seu programa internalista sobre uma dinâmica e uma lógica subjacentes. $\mathrm{O}$ argumento se torna a rota do "ée" para o "dever ser", a partir da qual se torna sua posição ética fundamental. Não se trata tanto de afirmar que o real é o racional que é o bem. É mais do que isso: o real e sua lógica são o bem (WATTS MILLER, 1996, p. 19). 
O olhar do sociólogo para as coisas sociais deve buscar então lógicas internas, que expliquem a causalidade dos acontecimentos. Durkheim pondera que esta lógica do real não é necessária e imanente, uma vez que devemos buscar reformas morais que se alinhem com a busca do "ideal humano" (DURKHEIM, 1898). É nesse sentido que há uma passagem do "é" para o "dever ser". Mesmo que conheçamos aquilo que "é", isso não implica que não possamos pensar em um "dever ser". As relações permeadas por violência, tanto física quanto simbólica, são completamente normais em qualquer sociedade moderna, mas isso não acarreta que a desejemos e incitemos sua continuidade. O normal no sentido de "dever ser" é a consecução do ideal humano na prática, o que segundo Durkheim só ocorrerá com a reforma moral tanto no âmbito das consciências individuais como nas coletivas.

Mas o queéesta rota normal do "dever ser", pela qual Durkheim buscava alinhar posição ética e finalidade prática da Ciência? Não que a Ciência deva se incumbir de problemas especificamente práticos, mas ela deve sempre estar subsidiada por um ideal humano que é pensado sob agudas influências das aspirações revolucionárias:

Ele [Durkheim] resume a ética básica do nosso tempo como o "ideal humano". É a ética universalista da "pessoa humana". Exige, como a cidade da moderna cidadania, uma "pátria humana" - ou, em um termo neokantiano, uma "república das pessoas". Significa o florescimento de todos como um "centro autônomo de pensamento e ação". Requer uma "ampla, verdadeira cultura humana". É pervertido pelo "sórdido comercialismo" que reduz moralidade ao interesse. Encontra expressão nas aspirações, embora utópicas, da Revolução Francesa. Estas não irão embora. Elas estão enraizadas no mundo moderno. Tentativas de rejeitá-las prolongarão o «triste conflito» de classe e intensificarão o mal-estar social e moral. (WATTS MILLER, 1996, p. 1). 
O normal é então a expressão desta ética básica do nosso tempo, este "ideal humano" preconizado por Durkheim. A pesquisa sociológica tem o papel de buscar o normal do que "é", mas também é papel do cientista pensar em um devir. Aqui se entrelaçam as instâncias do fazer científico através da concepção de um cientista engajado com a mudança social. Como sustenta Watts Miller (1996), o normal liga o "é" com o "dever ser" e articula a complexa relação entre estruturas e ideais.

\section{ConsideraÇões FINAIS}

No percurso que traçamos até aqui, pudemos apreender uma discussão sobre o conceito de normal em que este é entendido não apenas como o "normalmente verificável", mas como uma condição para a consecução de fins, sendo a disseminação do ideal humano a finalidade última. Esse elemento utópico, combustível da mudança social, foi ironicamente o fator decisivo para que, para muitos autores (ARON, 2002; FERNANDES, 1994; FREITAG, 2002; NISBET, 1974; PARSONS, 1968) Durkheim fosse entendido como um conservador. Sem dúvida, essas interpretações devem ser entendidas no contexto da história da tradição sociológica, que ainda trabalha para superar as dualidades clássicas que constituíram seu imaginário, como a da ordem $x$ conflitualidade e estrutura $x$ ação, e que tenderam a reificar a obra durkheimiana como sendo a matriz das teorias da ordem e da estrutura. Ainda que diversos esforço estejam sendo feitos no sentido de reinventar essa história, apresentando, por exemplo, a teoria da ação que está presente na obra do autor (RAWLS, 2004), é preciso reconhecer que existe um longo caminho a ser percorrido para que o autor seja compreendido a partir de suas premissas intelectuais, de seus contexto histórico e do potencial imanente para se pensar o presente. 
No caso específico da questão que propomos analisar aqui, cabe ainda mencionar uma dificuldade adicional, que resulta do caráter problemático do próprio texto do autor, que não fornece todos os elementos necessários para se compreender sua tese acerca de sua concepção sobre a finalidade prática da ciência. A discussão que mobilizamos aqui teve como intuito fornecer elementos importantes para uma apreensão mais abrangente do sentido mais complexo de seu pensamento, e que permite sugerir mais do que julgar Durkheim quanto a isso, devemos pensar as possíveis saídas cogitadas para a elucidação da questão, tomando de empréstimo suas ideias e fortificando-as em novos desenvolvimentos teóricos.

Evidentemente, não se trata de eximir o autor de críticas ou aspirar a uma construção teórica isenta de falhas. Trata-se, ao contrário, de chamar a atenção para a necessidade de compreensão do autor a partir de seus próprios termos, inserindo-o no contexto histórico e intelectual com o qual seu pensamento dialoga. E, na medida do possível, trata-se, ainda, de buscar na complexidade muitas vezes pouco percebida elementos que se mostrem relevantes para a prática sociológica no presente. Acreditamos que o debate acerca da função prática da Ciência mantém-se como uma intrigante questão para a sociologia contemporânea, e os modos de fazê-lo permanecem um desafio constante.

No início da presente discussão mencionamos a existência de numerosas cisões no âmbito da teoria sociológica (e que muitas vezes ainda é presente), transformada em uma premissa segunda a qual se assumia que a adoção das ideias de um autor excluiria a adesão às ideias de outros, como exemplificado na dualidade clássica entre ordem e conflito. A absorção dos clássicos da sociologia se deu amplamente nessa perspectiva, centrada na escolha ideológica sem que houvesse maior verificação de facto nos diferentes sentidos que as teorias abarcam. Mas há um prelúdio de mudança por meio 
de estudos mais engajados com o conteúdo da obra durkheimiana (WEISS; BENTHIEN, 2012). Este artigo pretendeu se inserir neste contexto, no sentido de arranhar a vasta superfície das teorias clássicas reconsiderando-as para que elas nos auxiliem no entendimento do universo social, buscando na renovada compreensão dos clássicos elementos que inspirem e renovem as teorias contemporâneas.

\section{REFERÊNCIAS}

ALEXANDER, Jeffrey C. Durkheimian sociology: cultural studies. Cambridge: Cambridge University Press, 1988.

ARON, Raymond. As etapas do pensamento sociológico. São Paulo: Martins Fontes, 2002.

BESNARD, Philippe; BORLANDI, Massimo; BUSINO, Giovanni. La sociologie durkheimienne: tradition et actualité. Genève: Droz, 2004.

BESNARD, Philippe; BORLANDI, Massimo; VOGT, Paul. Division du travail et lien social: la thèse de Durkheim un siècle après. Paris: Presses universitaires de France, 1993.

COMTE, Auguste. Os pensadores. São Paulo: Abril Cultural, 1978.

DURKHEIM, Émile. As regras do método sociológico. São Paulo: Martins Fontes, 2007.

DURKHEIM, Émile. Da divisão do trabalho Social. São Paulo: Martins Fontes, 1999.

DURKHEIM, Émile. Education et sociologie. Paris: Presses Universitaires de France, 1922.

DURKHEIM, Émile. L'Individualisme et les Intellectuels. Revue Bleue, Paris,v. 10, n. 35, p. 7-13, 1898.

DURKHEIM, Émile; WATTS MILLER, William. Montesquieu: quid secundatus politicae scientiae instituendae contulerit. Oxford: Durkheim Press, 1997.

FERNANDES, Heloisa. Sintoma social dominante e moralização infantil. São Paulo: Escuta/Edusp, 1994.

FREITAG, Bárbara. Itinerários de antígona: a questão da moralidade. São Paulo: Papirus, 2002. 
GURVITCH, Georges. La Science des Faits Moraux et la Morale Théorique chez Émile HAMILTON, Peter (Org.). Émile Durkheim: critical Assessments. London: Routledge, 1995.

JOAS, Hans; KNÖBL, Wolfgang. Social theory: twenty introductory lectures. Cambridge: Cambridge University Press, 2009.

JONES, Susan. Charles Renouvier and Émile Durkheim: les regles de la methode sociologique. Sociological Perspectives, New York, v. 38, n. 1, p. 27-40, 1995.

JONES, Susan. Durkheim reconsidered. Cambridge: Polity, 2001.

KANT, Immanuel. Crítica da razão prática. Lisboa: Edições 70, 2008.

LACAPRA, Dominick. Émile Durkheim: sociologist and philosopher. New York: Cornell University Press, 1972.

LOGUE, William. Charles renouvier, philosopher of liberty. Louisian: Lousiana State University Press, 1993.

LUKES, Steven. Emile Durkheim, his life and work: a historical and critical study. Stanford: Stanford University Press, 1985.

MASSELLA, Alexandre. O naturalismo metodológico de Émile Durkheim. São Paulo: Humanas; Goiânia: Ed. UFG, 2006.

NISBET, Robert. Conservatism and sociology. American Journal of Sociology, Chicago, v. 58, n. 2, p. 167-175, 1952.

NISBET, Robert. The sociology of Emile Durkheim. New York: Oxford University Press, 1974.

PARSONS, Talcott. The structure of social action. New York: Free Press; London: Collier Macmillan, 1968.

RAWLS, Anne Warfield. Epistemology and practice: Dukheim's the elementary forms of religious life. Cambridge/New York: Cambridge University Press, 2004.

RENOUVIER, Charles. Manuel Républicain de L'Homme et du Citoyen. Paris: Pagnerre, 1848.

RENOUVIER, Charles. Science de la Morale. Paris: Ladrange, 1869.

RILEY, Alexander. Durkheim contra Bergson? The Hidden Roots of Postmodern Theory and the Postmodern "Return" of the Sacred. Sociological Perspectives, Pacific Sociological Association, vol. 45, no 3, 2002, p. 243-265. 
ROSATI, Massimo. Ritual and the sacred : a neo-Durkheimian analysis of politics, religion and the self. Farnham: Ashgate, 2009.

ROSATI, Massimo; SANTAMBROGIO, Ambrogio; ALEXANDER, Jeffrey. Emile Durkheim, contributi ad una rilettura critica. Roma: Meltemi, 2002.

SILVA, Franklin Leopoldo. Elementos para a imagem moral do homem na filosofia francesa do final do Século XIX e início do século XX. 1980. Tese (Doutorado em Filosofia) - Universidade de São Paulo, São Paulo, 1980.

TURNER, Stephen. Emile Durkheim: sociologist and moralist. London: Routledge, 1993.

WALLWORK, Ernest. Durkheim morality and milieu. Cambridge: Harvard University Press, 1972.

WATTS MILLER, William. A Durkheimian quest: solidarity and the sacred. Oxford: Berghahn Books, 2012.

WATTS MILLER, William. Durkheim, morals and modernity. Montreal: McGillQueens University Press, 1996.

WATTS MILLER, William. Investigando o projeto de Durkheim para a constituição de uma Ciência Social. In: WEISS, Raquel (Org.). Durkheim: 150 anos. Belo Horizonte: Argumentum, 2009. p. 39-68.

WEISS, Raquel. A concepção de educação de Durkheim como chave para a passagem entre Positivo e Normativo. In: WEISS, Raquel (Org.). Durkheim: 150 anos. Belo Horizonte: Argumentum, 2009.

WEISS, Raquel. Émile Durkheim e a Fundamentação Social da Moralidade. 2010. Tese (Doutorado em Filosofia) - Universidade de São Paulo, 2010.

WEISS, Raquel; BENTHIEN, Rafael. A redescoberta de um sociólogo: considerações sobre a correspondência de Émile Durkheim a Salomon Reinach. Novos Estudos CEBRAP, n. 94, p. 133-149, 2012. 